\title{
ETHNIC IDENTITY AND SELF-ESTEEM OF CHINESE MALAYSIAN UNIVERSITY STUDENTS: DOES UNIVERSITY SOCIAL CONTEXT MATTER?
}

\author{
Amy Lou Lundell*, Thirunaukarasu Subramaniam** \& \\ Chong Wu Ling \\ *First author, ${ }^{* *}$ Corresponding author \\ Department of Southeast Asian Studies \\ Faculty of Arts and Social Sciences \\ University of Malaya \\ (amylundell@gmail.com, stkarasu@um.edu.my, \\ chong.wu.ling@um.edu.my) \\ DOI: https://doi.org/10.22452/jati.vol24no1.11
}

\begin{abstract}
Ethnic Chinese constitute a large, albeit minority, group in Malaysian society. Within this group, Chinese Malaysians come from a wide variety of linguistic, religious, and educational backgrounds. The overall purpose of this study was to gain a better understanding of the impact of university social context on ethnic identity and self-reported global self-esteem for Chinese Malaysian university students. To conduct this study, a total of 628 students were sampled from two universities and from different social backgrounds. Students answered a questionnaire about their ethnic identity, self-esteem, and demographic background. The relationship between ethnic identity and self-esteem was examined and the most significant predictors of ethnic identity for Chinese Malaysian university students were discovered. Analysis revealed that national context as well as childhood and adolescence, as opposed to university education or context, play a key role in student ethnic identity formation.
\end{abstract}

Keywords: ethnic identity, self-esteem, minority, social context, Malaysia

\section{Introduction}

Malaysia is an incredibly racially diverse country consisting of people from many backgrounds and ethnicities. Within all this diversity there are three distinct people groups that stand out as the largest in the country: Malay, 
Chinese, and Indian. While Malay people do make up the majority of the population of Malaysia, about 22.6 percent of Malaysians are part of that second category, Chinese (The world factbook 2013-14, 2017). This means that out of the approximately 31 million citizens of Malaysia, there are about 7 million Chinese Malaysian individuals living in Malaysia today (The world factbook 2013-14, 2017). The term "ethnic Chinese" is used in this study to refer to anyone who is ethnically Chinese but who lives outside of the People's Republic of China and Taiwan. The ethnic Chinese in Malaysia can be considered as a large minority group in Malaysia in comparison to Malaysian Indian. Chinese Malaysians are involved in most areas of society-most occupations, most socioeconomic classes-and their overall well-being will therefore have a profound impact on Malaysian society. One key factor that plays an important role in the mental, emotional, and social health of any minority group, including the ethnic Chinese in Malaysia, is their collective ethnic identity. This study defines ethnic identity as "the degree to which one views oneself as a member of a particular ethnic group" (Tsai, Chentsova-Dutton, \& Wong, 2002, p. 42). The notion of ethnic identity and the impact of this identity on an individual's self-esteem and wellbeing will be further explored and explained throughout this paper. It is essential to view the identity of this ethnic Chinese group as an entity and to determine the factors that play important roles in the formation of this identity -especially among young adults - as this information will have many repercussions on the nation of Malaysia in multiple areas, namely politically, socially and economically (shown in Wan Husin, 2013; Ting, 2014; Tan, 2005). In short, because the Chinese make up a rather large percentage of the population of Malaysia and because ethnic identity plays such a central role in an individual's sense of well-being, this study aims to gain a deeper understanding of Chinese Malaysian students' ethnic identity and then through that understanding it is certainly a goal to see increased health of this identity in the years to come. In addition, this study of the ethnic identity of Chinese Malaysian young adults intends to explore some unique differences of ethnic identification within this seemingly homogenous, but diverse, minority group.

As ethnic identity is studied in this paper, it should not be confused with racial identity or with national identity, both of which are indeed related to ethnic identity in most cases. Racial identity and national identity can also be explored along the same theoretical lines of social identity theory, but this study will not focus on Malaysian (national) identity or Asian (racial) identity, but instead on Chinese ethnicity alone. As confirmed by Chin (2013) in one of his final remarks in his paper on the ethnic socialisation of Malaysian university students: "In the Malaysian context, Malaysians will continue to identify 
themselves according to ethnic lines" (p. 585). In other words, topics such as ethnicity, ethnic relations, and ethnic groups remain salient in Malaysia today.

As this study seeks to grasp a better understanding of the ethnic identity of Chinese Malaysian university students, the following statements encompass the objectives of the study described in this paper:

1.to discover (a) the strength with which Chinese Malaysian students selfidentify with their Chinese ethnic identity and (b) their self-reported self-esteem.

2. to compare and analyze the correlation between ethnic identity and self-esteem for Chinese Malaysian university students.

3. to explore the effect of university social context on ethnic identity for Chinese Malaysian university students.

The study described in this paper was conducted with the goal of testing the following two main hypotheses:

1. The correlation between ethnic identity and self-esteem will be significant and positive for students atten ding University of Malaya (UM), a predominantly non-Chinese university, while there will be no significant relationship between ethnic identity and self-esteem for students attending Universiti Tunku Abdul Rahman (UTAR), a university dominated by Chinese Malaysian students.

2. Students attending $U M$, a predominantly non-Chinese university, will score significantly higher on ethnic identity than students attending UTAR, a university dominated by Chinese Malaysian students.

\section{Selected Literature}

\section{Theoretical Perspective}

This study is theoretically anchored in ethnic identity theory. Ethnic identity is defined as "the degree to which one views oneself as a member of a particular ethnic group" (Tsai et al., 2002, p. 42). The notion of ethnic identity finds its roots in Social Identity Theory, which comes from the field of social psychology. Social Identity Theory originated in the 1970s and the 1980s with two social psychologists: Henri Tajfel and John Turner. In short, Social Identity Theory is centered on how people view themselves as part of a larger group, how they view their group in comparison with other groups, and then how these views affect their behavior (Tajfel \& Turner, 1979). Every individual belongs to many different groups in life, and Social Identity Theory can be applied to a vast number of kinds of groups to which an individual might belong - ethnicity, race, 
nation, occupation, religion, social class, family or team. The focus of this studyethnic identity - is just one specific type of group identity relating to ethnicity only.

Zooming in on ethnic identity specifically as just one branch of Social Identity Theory, one important and well-studied aspect of ethnic identity is ethnic identity development, or how one's ethnic identity is created gradually over time. The most current and widely accepted developmental model of ethnic identity was proposed by Phinney (1989). Phinney's model is an extension of Marcia's (1966) earlier developmental model of ego identity formation, which has more broad applications than ethnic identity alone. Marcia's model is based on Erikson's (1956) ideas of ego identity and identity diffusion. Within his developmental model of ego identity formation, Marcia identified four identity statuses that describe four different stages in which an individual might be with regard to his or her ego identity formation based on the presence or absence of exploration of and commitment to one's identity. Individuals who have neither explored nor committed to an identity are known as diffuse, individuals who have committed to an identity without any exploration are known as foreclosed, individuals who are engaging in exploration but have not committed to an identity are in moratorium, and individuals who have both explored and committed to an identity are termed identity-achieved (Marcia, 1966).

Phinney's developmental model of ethnic identity uses these same four terms based on exploration and commitment to describe ethnic identity statuses, but her definitions of each status refer strictly to ethnicity. Phinney's definitions of ethnic identity processes and statuses will be used in this study (for further discussion, refer to Phinney, Jacoby, \& Silva, 2007, p. 479).

Phinney (1990) agrees with most literature on the topic when she concludes that individuals typically encounter progression through these stages of ethnic identity development during adolescence. Erikson (1956) was the first to discuss the experience individuals typically have during adolescence that causes them to explore group identification and he attributes this to some sort of crisis. This crisis and then exploration Erikson discusses is in the same vein as the exploration that sends individuals through the stages of ethnic identity development.

\section{Ethnic Identity in Malaysia}

Lee's (2009) study, which sought to understand the formation of Chinese identity in Malaysia on a micro level by looking at social actors, or individuals, concludes that "the source of knowledge of the Chinese about their identity includes experience, reading and [formal and informal] socialization" (p. 37). In other words, the Chinese Malaysian individuals in this study engaged in some 
activities that influenced their ethnic identity development. In addition, Lee (2009) concludes that context influenced the informants' ethnic identity, as did their varied cultural backgrounds, such as education, religion, family, stages of life, and linguistic ability.

Chin (2013) studied the ethnic socialisation experiences of both Malay and Chinese Malaysian university students and considered what sort of specific experiences students encountered that shaped their ethnic identity and brought them to where they are today. He summarizes Nagata's (1980) thought that "ethnic consciousness is an outcome of actions taken by the members of an ethnic group to commit their alignment to their ethnic group" (Chin, 2013, p. 584). Though an individual can accomplish some of these actions alone, this study concluded that the most influential people in the ethnic socialisation of an individual were that individual's family members and peers from the same ethnic group.

Granhemat, Chan, and Abdullah (2014) published a study regarding the ethnic identity of undergraduate students at a public university in Malaysia. They agreed that Malaysia is an exceptional country in which to study ethnic identity because its citizens do come from such a wide variety of ethnic backgrounds. Granhemat et al. (2014, p. 31) found that, "there is variability in trajectories among ethnic groups in different geographical locations" and also confirmed that "ethnic identity can be measured".

\section{Relationship between Ethnic Identity and Self-Esteem}

The four aforementioned ethnic iden tity statuses (and Marcia's more general ego identity statuses) are more than just labels for individuals, but are also indicators of these individuals' self-esteem. Even before Tajfel and Turner outlined a theory regarding social identity, psychologist Kurt Lewin began the conversation of social identity by stating that one of the key factors in an individual's ability to maintain a sense of well-being is his or her identification within a group. According to Lewin (1948), a strong sense of group identification contributes to a healthy sense of well-being and a positive self-esteem.

Many studies have been conducted in more recent years to test, explore, and confirm Lewin's theory regarding the direct and strong link between group identification and an individual's healthy sense of well-being with a specific focus on ethnic group identification. A study on ethnic identity and self-esteem among Asian and European Americans was conducted in Hawaii and the United States (US) mainland. In this study the authors state, "Adolescents who can resolve uncertainties about their ethnicity via exploration generally develop an affirmation with their ethnic group, feel comfortable with who they are, and manifest high self-esteem, self-confidence, and a sense of purpose in life" (Xu, 
Farver, \& Pauker, 2015, p. 63). In another study on ethnic identity and selfesteem among Mexican-origin adolescents in the Southwest of the US mainland, the author explored levels of self-esteem among adolescents in a number of different social contexts and found that "significant relationships emerged between ethnic identity and self-esteem among adolescents in all school settings" (Umaña-Taylor, 2004, p. 139). A positive relationship between ethnic identity and self-esteem was observed among ethnic minority adolescents (e.g., Asian, African American, Latino, Native American) in studies conducted by Carlson, Uppal, and Prosser (2000); Martinez and Dukes (1997); Phillips Smith, Walker, Fields, Brookins, and Seay (1999); Phinney (1992); Phinney and Alipuria (1990); Phinney, Cantu, and Kurtz (1997); Phinney and Chavira (1992); Phinney, Chavira, and Tate (1993); and Phinney, Dupont, Espinosa, Revill, and Sanders (1994) among others. Indeed, many researchers have explored the relationship between ethnic identity and self-esteem and have discovered similar results: young adults who have explored and then understood their place in an ethnic group tend to be more confident in who they are as individuals and in what role they play in society.

\section{Self-Esteem among Asians}

Bachman, O'Malley, Freedman-Doan, Trzesniewski, and Donnellan (2011) studied the self-reported self-esteem of $8^{\text {th }}, 10^{\text {th }}$, and $12^{\text {th }}$-grade students in the US and drew conclusions as they compared self-esteem scores from different races/ethnicities and genders. As they focused their study on students in the US, Bachman et al. (2011) included Asian American students in their study. Bachman et al. (2011) concluded that cultural differences surrounding the values of "group harmony...modesty, a sense of connectedness, and conformity" would likely affect the expression of self-esteem and explain why Asian Americans report lower self-esteem scores than White or African American students (p. 447). These values and socialisation practices that lead to relatively low self-reported selfesteem scores are also applicable in the Chinese Malaysian context. However, this does not skew data in this study because Asian students are being compared with one another and not with students of different ethnicities without these values and socialisation practices.

Cai, Brown, Deng, and Oakes (2007) also studied the topic of self-esteem among Asians, specifically among Chinese university students, in two related studies. One study used the Rosenberg (1979) Self-Esteem Scale in addition to two other self-report questionnaires as supplements, while the other study used a measure of modesty developed by Whetstone, Okun, and Cialdini (1992) and used by Kurman and Sriram (Kurman \& Sriram, 2002; Kurman, 2003). While Cai et al. (2007) and many other scholars have indicated that Asians do score lower 
on self-esteem scales than do Westerners, these studies concluded that Asians do not like themselves less than do Westerners, but when self-reporting about their self-esteem they score lower than Westerners because of the nature of selfreporting one's positive characteristics. In other words, while a self-report selfesteem scale such as the Rosenberg (1979) Self-Esteem Scale used in this study may seem to indicate a slightly lower global self-esteem for Asians, this is only an indication of lower cognitive self-evaluations. In summary, these studies by Cai et al. (2007) show that the Rosenberg (1979) Self-Esteem Scale is indeed a reliable scale to measure global self-esteem among Asians if comparisons are being made between individuals of the same ethnicity (i.e. Chinese Malaysian) because in this case the bias of varying attitudes towards cognitive selfevaluations will not exist.

\section{Research Methodology}

\section{Participants}

A sample of 327 Chinese Malaysian undergraduate students from UTAR and 301 Chinese Malaysian undergraduate students from UM were surveyed, giving a total of 628 students sampled. There were slightly more female $(N=356,56.7 \%)$ than male students $(N=272,43.3 \%)$ in the study. The age of the students ranged from 18 to 29 years, with an overall mean of about 21 years $(M=20.76, S D=1.32)$.

\section{Materials}

Each respondent completed a survey with three parts: a set of demographic questions, a tool to assess ethnic identity, and a tool to assess self-esteem. Some of the demographic questions include age, gender, religion, first language, and hometown, faculty/school within their university, household income, and parents' education levels.

\section{(a) Ethnic Identity Assessment}

Phinney's (1992) Multigroup Ethnic Identity Measure-Revised (MEIM-R) was used to assess students' ethnic identity. The original Multigroup Ethnic Identity Measure (MEIM), composed of 14 items, was revised over the years to increase its reliability (Phinney \& Ong, 2007). Herrington (2014) performed a reliability generalization analysis and compared the data between the MEIM-R and the original MEIM, concluding that the MEIM-R can be used with confidence. The MEIM- $R$ is considered bi-dimensional and consists of 6 total items -3 that measure exploration and 3 that measure commitment. Factor analysis was performed to confirm the bi-dimensionality of the MEIM-R for this study. Answers were given on a 4-point Likert scale with the following four options: 
strongly agree, agree, disagree, and strongly disagree. A higher score on the MEIM-R indicates a more developed sense of ethnic identity (Phinney \& Ong, 2007). The Cronbach's alpha scores for the MEIM-R for this study were $\alpha=0.84$ for UM, $\alpha=0.71$ for UTAR, and $\alpha=0.79$ for the overall data set when students from both universities are combined. The Cronbach's alpha scores for the exploration and commitment subscales of the MEIM-R are reported in Table 3.

\section{(b) Self-Esteem Assessment}

Rosenberg's (1979) Self-Esteem Scale (RSE) was used to assess students' selfesteem. This scale consists of 10 items that measure self-worth -5 items that are worded positively and 5 items that are worded negatively. Answers were given on a 4-point Likert scale with the following four options: strongly agree, agree, disagree, and strongly disagree. When the sum score of the scale is calculated, the 5 negatively-worded items are reverse scored so that they can be combined with the 5 positively-worded items. A higher score on the RSE Scale indicates higher self-esteem (Rosenberg, 1979). There is an ongoing debate in the academic world about whether the RSE Scale is unidimensional or bi-dimensional. Researchers often treat the RSE Scale as a unidimensional scale, disregarding many factor analysis studies that indicate it is bi-dimensional (Supple, Su, Plunkett, Peterson, \& Bush, 2013). The two commonly proposed factors follow the wording of the items: the five positively-worded items $(1,3,4,7$, and 10) assess positive self-esteem while the five negatively-worded items $(2,5,6,8$, and 9) assess negative self-esteem. Researchers have found differences when analyzing associations between theoretically related constructs and positive or negative self-esteem (Ang, Neubronner, Oh, \& Leong, 2006; Farruggia, Chen, Greenberger, Dmitrieva, \& Macek, 2004; Owens, 1993, 1994). For example, Ang et al. (2006) found two distinct factors (positive and negative self-esteem) for the RSE Scale in a sample of 153 seventh-grade Asian students from Singapore, which is an Asian-based school sample with similarities to this study in Malaysia. Although the factor structure debate continues, the RSE Scale will be considered bi-dimensional in this study based on the foundation of existing literature with one factor for positive self-esteem and one factor for negative selfesteem. Factor analysis was performed to confirm the bi-dimensionality of the RSE Scale for this study.

The original Cronbach's alpha scores for the RSE Scale for this study were $\alpha=0.82$ for UM, $\alpha=0.74$ for UTAR, and $\alpha=0.79$ for the overall data set when students from both universities are combined. However, item 8 ("I wish I could have more respect for myself") was found to be negatively or weakly correlated with the other nineitems in the scale, and this was found to be true at both schools, UM and UTAR, so item 8 was removed from all further analyses 
regarding the RSE Scale. The new, recalculated Cronbach's alpha scores for the RSE Scale for this study were $\alpha=0.86$ for UM, $\alpha=0.78$ for UTAR, and $\alpha=0.82$ for the overall data set when students from both universities are combined. The Cronbach's alpha scores for the positive and negative self-esteem subscales of the RSE Scale are reported in Table 4.

\section{Procedure}

At both UTAR and UM, students completed the three-part survey described above either on a physical paper form or an essentially identical electronic Google Form. Students submitting the survey electronically used either one of our tablet devices or their own hand phone or laptop to complete the survey. In both cases, whether completing electronically or on paper, we approached many students in various locations around the UM and UTAR campuses (canteens, libraries, common areas, etc.) and politely asked if they would participate in the study by completing the survey. Most students were very willing to participate. We also sent a link for the electronic version of the survey to some respondents whom we already knew at UM rather than approaching them as strangers. Data collection occurred over the course of five months from 25 October 2016 to 23 March 2017.

Table 1: Means, Standard Deviations, and Sample Sizes for Ethnic Identity and Self-Esteem Scores by Year in University and Gender for UTAR Students

\begin{tabular}{|c|c|c|c|c|c|c|c|}
\hline \multirow[b]{2}{*}{$\begin{array}{l}\text { Year } \\
\text { University }\end{array}$} & \multirow[b]{2}{*}{ in } & \multirow[b]{2}{*}{ Gender } & \multicolumn{2}{|c|}{ Ethnic Identity } & \multicolumn{2}{|c|}{ Self-Esteem } & \multirow[b]{2}{*}{$N$} \\
\hline & & & $M$ & $S D$ & $M$ & $S D$ & \\
\hline \multirow{3}{*}{\multicolumn{2}{|c|}{1}} & Male & 17.20 & 2.18 & 17.10 & 3.53 & 59 \\
\hline & & Female & 17.52 & 2.12 & 16.12 & 2.86 & 86 \\
\hline & & Total & 17.39 & 2.15 & 16.52 & 3.17 & 145 \\
\hline \multirow{3}{*}{\multicolumn{2}{|c|}{2}} & Male & 17.44 & 2.03 & 15.87 & 3.13 & 54 \\
\hline & & Female & 17.28 & 1.61 & 16.05 & 3.58 & 75 \\
\hline & & Total & 17.35 & 1.79 & 15.98 & 3.39 & 129 \\
\hline \multirow{3}{*}{\multicolumn{2}{|c|}{3}} & Male & 18.18 & 2.68 & 16.59 & 3.35 & 22 \\
\hline & & Female & 18.55 & 1.95 & 17.05 & 3.08 & 22 \\
\hline & & Total & 18.36 & 2.32 & 16.82 & 3.19 & 44 \\
\hline \multirow{3}{*}{\multicolumn{2}{|c|}{4}} & Male & 17.33 & 2.07 & 18.33 & 3.27 & 6 \\
\hline & & Female & 16.33 & 2.89 & 15.33 & 3.79 & 3 \\
\hline & & Total & 17.00 & 2.24 & 17.33 & 3.54 & 9 \\
\hline \multirow{3}{*}{\multicolumn{2}{|c|}{ Total }} & Male & 17.45 & 2.21 & 16.60 & 3.37 & 141 \\
\hline & & Female & 17.53 & 1.95 & 16.19 & 3.20 & 186 \\
\hline & & Total & 17.50 & 2.06 & 16.37 & 3.28 & 327 \\
\hline
\end{tabular}


This kind of sampling is considered homogenous purposive sampling because we selected respondents who specifically fit the criteria of being undergraduate students and being of Chinese Malaysian ethnicity (Patton, 1990). Given that this procedure is technically non-probability sampling, the sample we obtained for this study is as representative of the population as possible given our limitations. See Tables 1 and 2 for details regarding the representative distribution of sampling across year in university and gender at each university.

Based on Table 1 above, for UTAR students the means for ethnic identity scores for Year 1, Year 2 and Year 4 male students seem to be more consistent. On the other hand, means for self-esteem scores for Year 1 and Year 2 female students appear to be more consistent. The lowest mean for ethnic identity scores is displayed among Year 4 female students and the highest is for Year 3 female students. The lowest mean for self-esteem scores is displayed for Year 4 female students and the highest is for Year 4 male students.

Table 2: Means, Standard Deviations, and Sample Sizes for Ethnic Identity and Self-Esteem Scores by Year in University and Gender for UM Students

\begin{tabular}{|c|c|c|c|c|c|c|}
\hline \multirow[b]{2}{*}{$\begin{array}{l}\text { Year } \\
\text { University }\end{array}$} & \multirow[b]{2}{*}{ Gender } & \multicolumn{2}{|c|}{ Ethnic Identity } & \multicolumn{3}{|c|}{ Self-Esteem } \\
\hline & & $M$ & $S D$ & $M$ & $S D$ & $N$ \\
\hline \multirow[t]{3}{*}{1} & Male & 17.72 & 2.59 & 16.72 & 2.96 & 29 \\
\hline & Female & 18.20 & 2.71 & 17.09 & 3.50 & 45 \\
\hline & Total & 18.01 & 2.66 & 16.95 & 3.28 & 74 \\
\hline \multirow[t]{3}{*}{2} & Male & 18.28 & 2.95 & 17.23 & 5.35 & 40 \\
\hline & Female & 17.46 & 2.67 & 16.68 & 3.16 & 59 \\
\hline & Total & 17.79 & 2.80 & 16.90 & 4.17 & 99 \\
\hline \multirow[t]{3}{*}{3} & Male & 16.80 & 2.88 & 17.11 & 3.99 & 54 \\
\hline & Female & 17.27 & 2.39 & 17.04 & 3.31 & 56 \\
\hline & Total & 17.04 & 2.64 & 17.07 & 3.64 & 110 \\
\hline \multirow[t]{3}{*}{4} & Male & 18.86 & 2.79 & 17.14 & 4.78 & 7 \\
\hline & Female & 17.70 & 3.13 & 17.80 & 2.94 & 10 \\
\hline & Total & 18.18 & 2.96 & 17.53 & 3.68 & 17 \\
\hline \multirow[t]{3}{*}{5} & Male & 14.00 & - & 14.00 & - & 1 \\
\hline & Female & - & - & - & - & 0 \\
\hline & Total & 14.00 & - & 14.00 & - & 1 \\
\hline \multirow[t]{3}{*}{ Total } & Male & 17.54 & 2.90 & 17.04 & 4.26 & 131 \\
\hline & Female & 17.61 & 2.63 & 16.97 & 3.27 & 170 \\
\hline & Total & 17.58 & 2.74 & 17.00 & 3.73 & 301 \\
\hline
\end{tabular}


Based on Table 2, for UM students the means for ethnic identity scores seem to be consistent for Year 2, Year 3 and Year 4 female students. The means for self-esteem scores for Year 2, Year 3 and Year 4 male students also appear to be more consistent. The highest mean is displayed for Year 4 male students for ethnic identity scores. For self-esteem scores, the highest mean is displayed for Year 4 female students.

The entirety of the survey was written in both English and Mandarin Chinese so that students were able to read either or both languages as they were answering the questions. Each of the three sections of the survey (demographic questions, Multigroup Ethnic Identity Measure-Revised, and Rosenberg SelfEsteem Scale) along with the letter of consent were originally written in English and were translated into Mandarin Chinese. Using both English and Mandarin Chinese on the survey was done to eliminate, or at least diminish, inaccurate readings of the questions, which could skew the results.

\section{Results}

\section{Factor Analysis of the Multigroup Ethnic Identity Measure-Revised}

Based on previous studies and previous factor analyses, the Multigroup Ethnic Identity Measure-Revised was found to have two distinct factors. The first factor is typically identified as "commitment" and includes items 2, 3, and 6, while the second factor is typically identified as "exploration" and includes items 1, 4, and 5 (Phinney \& Ong, 2007). Before continuing with other analyses of the data, a factor analysis was conducted to assess the validity of the assumed existing factors within this current study. The factor loading matrix is presented in Table 3 and shows that the factors extracted in this study were in agreement with the factors proposed by Phinney and Ong (2007). Items 2, 3, and 6 load strongly on to factor 1 and are labelled as the "commitment" factor while items 1 , 4 , and 5 load strongly onto factor 2 and are labelled as the "exploration" factor.

Table 3: Factor Loadings and Internal Consistency Coefficients Based on a Principal Components Analysis with Oblimin Rotation for All Six Items from the Multigroup Ethnic Identity Measure - Revised (Phinney \& Ong, 2007) (N=628)

\begin{tabular}{|c|c|c|c|}
\hline \multirow[b]{2}{*}{ Items } & \multicolumn{2}{|c|}{ Component } & \multirow[b]{2}{*}{$\begin{array}{l}\text { Cronba } \\
\text { ch's } \alpha^{2}\end{array}$} \\
\hline & Commitment & Exploration & \\
\hline $\begin{array}{l}2 \text { I have a strong sense ofbelonging to my own } \\
\text { ethnic group. }\end{array}$ & .942 & & .738 \\
\hline $\begin{array}{l}6 \text { I feel a strong attachment towards my own ethnic } \\
\text { group. }\end{array}$ & .801 & & \\
\hline
\end{tabular}




\begin{tabular}{l}
\hline I understand well what my ethnic group \\
membership means to me. \\
$\begin{array}{l}5 \text { I have often talked to other people in order to } \\
\text { learn more about my ethnic group. }\end{array}$ \\
$\begin{array}{l}\text { I I have often done things that will help me } \\
\text { understand my ethnic background better. }\end{array}$ \\
$\begin{array}{l}\text { 1 I have spent time trying to find out more about } \\
\text { my ethnic group, such as its history, traditions, and } \\
\text { customs. }\end{array}$
\end{tabular}

Extraction Method: Principal Component Analysis.

Rotation Method: Oblimin with Kaiser Normalization.

Note: All factor loadings are significant at the $\mathrm{p}<.001$ level; Factor loadings $<.3$ are suppressed.

\section{Factor Analysis of the Rosenberg Self-Esteem Scale}

Based on previous studies and factor analyses described earlier, the RSE Scale has been found to have two distinct factors. The first factor is typically identified as "positive self-esteem" and includes items 1, 3, 4, 7, and 10, while the second factor is typically identified as "negative self-esteem" and includes items 2, 5, 6, 8 and 9 (Supple et al., 2013). As a reminder, however, item 8 ("I wish I could have more respect for myself") was found to be negatively or weakly correlated with the other nine items in the RSE Scale, so item 8 was removed from all further analyses regarding the RSE Scale and was not included in this factor analysis. Before continuing with other analyses of the data, a factor analysis was conducted to assess the validity of the assumed existing factors within this current study.

Table 4: Factor Loadings and Internal Consistency Coefficients Based on a Principal Components Analysis with Oblimin Rotation For Nine Items from the Rosenberg Self-Esteem Scale (Rosenberg, 1979) $(\mathrm{N}=628)$

\begin{tabular}{|c|c|c|c|}
\hline \multirow[b]{2}{*}{ Items } & \multicolumn{2}{|c|}{ Component } & \multirow[b]{2}{*}{ Cronbach's } \\
\hline & Positive & Negative & \\
\hline 4 I am able to do things as well as most other people. & .822 & & .746 \\
\hline 3 I feel that I have a number of good qualities. & .754 & & \\
\hline 1 On the whole, Iam satisfied with myself. & .707 & & \\
\hline $\begin{array}{l}7 \text { I feel that I'm a person of worth, at least on an equal } \\
\text { plane with others. }\end{array}$ & .580 & & \\
\hline 10 I take a positive attitude toward myself. & .547 & & \\
\hline 6 I certainly feel useless at times. & & -.910 & .781 \\
\hline 5 I feel I do not have much to be proud of. & & -.747 & \\
\hline
\end{tabular}


\begin{tabular}{ll}
\hline 2 At times, I think I am no good at all. & -.736 \\
9 All in all, I am inclined to feel that I am a failure. & -.616
\end{tabular}

Extraction Method: Principal Component Analysis.

Rotation Method: Oblimin with Kaiser Normalization.

Note. All factor loadings are significant at the $\mathrm{p}<.001$ level; Factor loadings $<.3$ are suppressed.

The factor loading matrix is presented in Table 4 and shows that the factors extracted in this study were in agreement with the factors proposed by many researchers, including Supple et al. (2013). Items 1, 3, 4, 7, and 10 load strongly onto factor 1 and are labelled as the "positive self-esteem" factor while items 2, 5, 6, and 9 load strongly onto factor 2 and are labelled as the "negative self-esteem" factor.

\section{Association between Sense of Ethnic Identity and Students' Self-Esteem (Hypothesis 1)}

Hypothesis 1 stated that the correlation between ethnic identity and self-esteem will be significant and positive for studen ts attending UM, a predominantly nonChinese university, while there will be no significant relationship between ethnic identity and self-esteem for students attending UTAR, a university dominated by Chinese Malaysian students.

A Pearson product-moment correlation coefficient was computed to assess the relationship between the MEIM-R score and the RSE score at each school. At UM $(N=301)$, there was a positive correlation between the two variables, $r=0.24, p<0.01$. Overall, there was a weak, positive correlation between MEIM-R score and RSE score for students at UM. Similarly, at UTAR ( $N$ $=327$ ), there was a positive correlation between the two variables, $r=0.17, p<$ 0.01. Overall, there was a weak, positive correlation between MEIM-R score and RSE score for students at UTAR. These results at both UM and UTAR indicate that increases in MEIM-R score were correlated with increases in RSE score. A statistically significant relationship emerged between ethnic identity (measured using the MEIM-R) and self-esteem (measured using the RSE Scale) for students at both schools.

Hypothesis 1 was partially supported. There was a significant and positive correlation between ethnic identity and self-esteem for students attending UM, and this finding supported the hypothesized correlation for UM students. There was also a significant and positive correlation between ethnic identity and self-esteem for students attending UTAR, but this finding did not support the hypothesized correlation for UTAR students. 


\section{Mean Difference in Ethnic Identity Variable (Hypothesis 2)}

Hypothesis 2 stated that students attending UM, a predominantly non-Chinese university, will score significantly higher on ethnic identity than students atten ding UTAR, a university dominated by Chinese Malaysian students.

The UTAR group $(N=327)$ was associated with a MEIM-R score $M=$ $17.50(S D=2.060)$. By comparison, the UM group $(N=301)$ was associated with a numerically higher MEIM-R score $M=17.58(S D=2.742)$. To test the hypothesis that the UTAR students and UM students were associated with statistically significantly different mean MEIM-R scores, an independent samples $t$-test was performed. As can be seen in Table 5, the UTAR and UM distributions were sufficiently normal for the purposes of conducting a $t$-test (i.e., skew $<|2.0|$ and kurtosis < $19.0 \mid$; Schmider, Ziegler, Danay, Beyer, \& Bühner, 2010). Additionally, the assumption of homogeneity of variances was tested via Levene's $F$ test, $F(554.922)=11.72, p=.001$, but the assumption was not satisfied. For this reason, the results of the independent samples $t$-test could not continue to be interpreted with confidence.

At this point, the evidence to determine whether or not Hypothesis 2 was supported was inconclusive and a new test was required.

Table 5: Descriptive Statistics Associated with MEIM-R Score for Each University

\begin{tabular}{llllll}
\hline & $N$ & $M$ & $S D$ & Skew & Kurtosis \\
\hline UTAR & 327 & 17.50 & 2.060 & 0.219 & 1.142 \\
UM & 301 & 17.58 & 2.742 & -0.298 & 1.598 \\
\hline
\end{tabular}

First Language, Religion, and Majority/Minority Statuses at Primary School, Secondary School, and University as Predictors of Students' Sense of Ethnic Identity

Multiple regression analysis was used to test if the first language, religion, and majority/minority statuses at primary school, secondary school, and university significantly predicted students' sense of ethnic identity from the perspective of three different, but related, dependent variables: the MEIM-R overall score, the sub-score of the "commitment" subscale, and the sub-score of the "exploration" subscale. For the MEIM-R overall score, the results of the regression indicated the predictors explained $3.9 \%$ of the variance $\left(R^{2}=.039, \mathrm{R}\right.$ squared adjusted $=.031$, $F(5,622)=4.99, p<.001)$. It was found that speaking Chinese as one's first language significantly predicted a high MEIM-R overall score $(\beta=1.23, p<.01)$, as did having Buddhism or Taoism as one's religion $(\beta=0.49, p<.05)$. For the 
sub-score of the "commitment" subscale, the results of the regression indicated the predictors explained $4.0 \%$ of the variance $\left(R^{2}=.040, \mathrm{R}\right.$ squared adjusted $=$ $.032, F(5,622)=5.14, p<.001)$. It was found that speaking Chinese as one's first language significantly predicted a high "commitment" sub-score $(\beta=0.77, p<$ $.01)$, as did atten ding a Chinese majority primary school $(\beta=0.41, p<.10)$. For the sub-score of the "exploration" subscale, the results of the regression indicated the predictors explained $2.3 \%$ of the variance $\left(R^{2}=.023\right.$, $\mathrm{R}$ squared adjusted $=.015$, $F(5,622)=2.95, p<.05)$. It was found that speaking Chinese as one's first language significantly predicted a high "exploration" sub-score $(\beta=0.45, p<.10)$, as did having Buddhism or Taoism as one's religion $(\beta=0.30, p<.05)$.

Using the results from this regression to continue to respond to Hypothesis 2, the fact that first language, religion, and primary school were significant predictors of ethnic identity, but university was not a significant predictor, reinforces the conclusion that the university social context does not have a significant effect on ethnic identity. Therefore, Hypothesis 2 was not supported.

Table 6: Multiple Regression Analyses for First Language, Religion, and Majority/Minority Statuses at Primary School, Secondary School, and University as Predictors of Students' Sense of Ethnic Identity

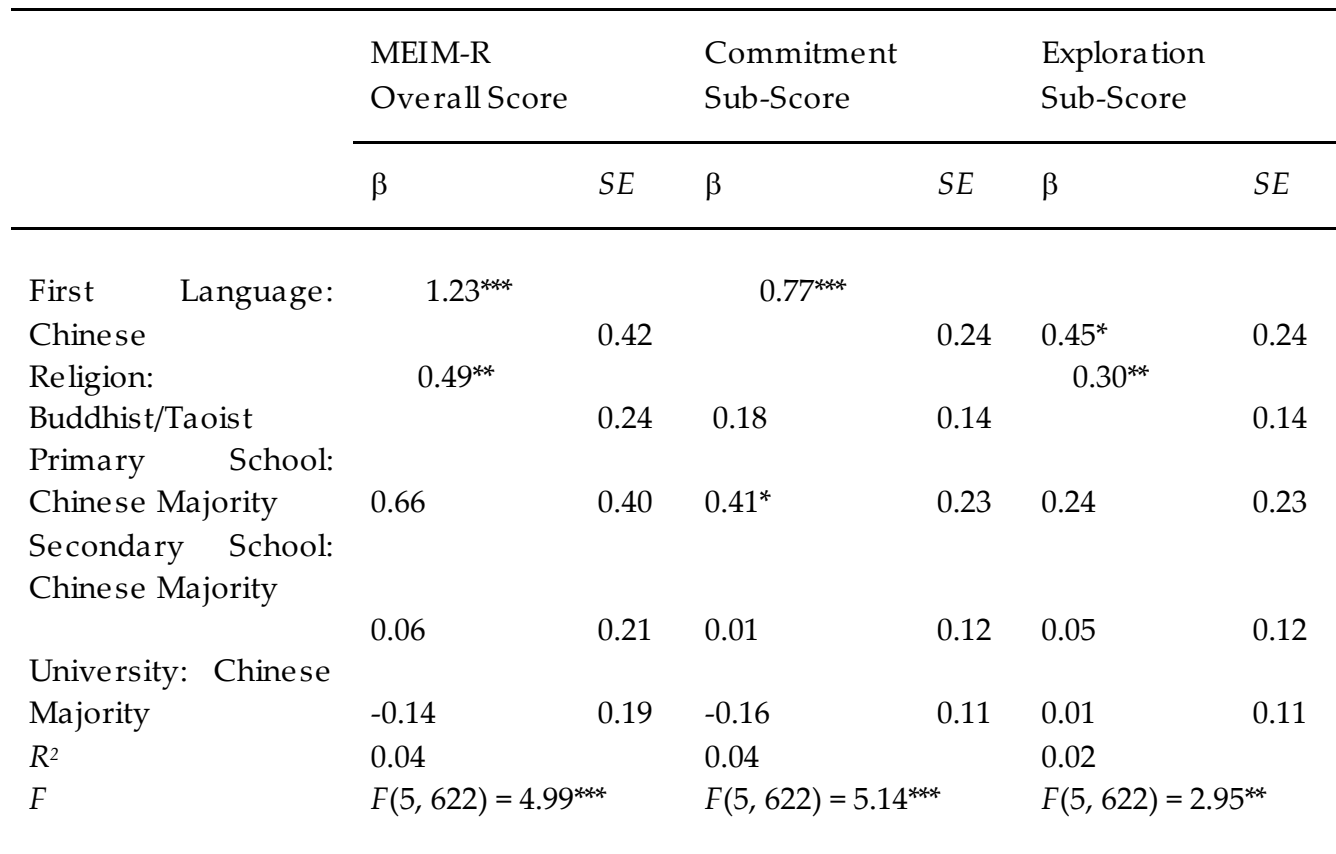

Note: ${ }^{*} p<.10 ;{ }^{* *} p<.05 ;{ }^{* * *} p<.01 ; \beta=$ unstandardized regression coefficient, $S E=$ standard error. 


\section{Discussion}

Hypothesis 1 addressed whether there was a significant correlation between ethnic identity and self-esteem for students atten ding UM, a predominantly nonChinese university and UTAR, a university dominated by Chinese Malaysian students. According to Tierney and Sirat (2008):

A 1971 law sought to reverse Chinese economic and social predominance and instead promoted a form of affirmative action for a majority of the population-ethnic Malays and other indigenous groups. The result has been a significant increase in the percentage of Malays who attend public universities, with a decrease of ethnic Chinese and Indians who attend. Prior to the implementation of the law, for example, Malay students accounted for less than one-third of the student population, but by 1985 they were close to two-thirds of all university students. Conversely, the Chinese had been about 56 percent of the student population in 1966, and 20 years later their numbers had shrunk to 29 percent. One by-product of the 1971 law is that non-Malay Malaysians (Chinese and Indians) have started their own private universities, and they account for the largest percentage of students in all private institutions.

It was predicted that there would be a significant and positive correlation between ethnic identity and self-esteem for students attending UM, and this was supported because a significant and positive correlation was found. Additionally, it was predicted that there would be no significant relationship between ethnic identity and self-esteem for students attending UTAR, but this was not supported because a significant and positive correlation was found.

These results regarding ethnic identity and self-esteem in varying social contexts are consistent with the results of Umaña-Taylor's (2004) and Juang, Nguyen, and Lin's (2006). The results of the study conducted by Umaña-Taylor (2004) showed a significant positive relationship between ethnic identity and self-esteem for adolescents from three school contexts, namely one that is predominantly Latino, one that is predominantly non-Latino, and one that is balanced Latino/non-Latino. Although effect sizes were small, which is true in this study as well, the findings were still significant. Similarly, Juang et al. (2006) studied how living in an ethnically concentrated (West Coast of the US) or ethnically dispersed (Midwest of the US) context affected ethnic identity and three aspects of psychosocial functioning: depression, self-esteem, and connectedness to parents for Asian American emerging adults (mean age of 
approximately 20). In summary, Juang et al. (2006) found a positive correlation between ethnic identity and self-esteem in general for their overall sample, but found that this correlation did not continue to be true when the effect of context was taken into account. Both Juang et al.'s (2006) study and the current study found ethnic identity and self-esteem to be significantly positively correlated in their overall samples.

These results regarding ethnic identity and self-esteem in varying social contexts differ from the results of Xu et al.'s (2015) study and Umaña-Taylor and Shin's (2007) study. The results from Xu et al.'s (2015) study showed that ethnic identity was significantly associated with self-esteem for Asian Americans in California (where they were a minority group), but not for Asian Americans in Hawai'i (where they were in the majority). Similarly, Umaña-Taylor and Shin (2007) studied the relationship between ethnic identity and self-esteem among African American, Latino, Asian American, and European American university students in two different contexts: California and the Midwest of the US Analyses were conducted for each ethnic group in each location, looking at the relationship between self-esteem and each of the following three subscales of the Ethnic Identity Scale (EIS): resolution, exploration, and affirmation. In summary, Umaña-Taylor and Shin's (2007) study found that the relation between ethnic identity and self-esteem can vary by ethnic group and by social context, which is a somewhat different finding than the similar ethnic identity/self-esteem correlation this current study found in two different social contexts.

Without considering the effect of social context, many other studies have also found a significant positive relationship between ethnic identity and selfesteem (Abu-Rayya, 2006; Bracey, Bamaca, \& Umaña-Taylor, 2004; Lum, 2008; Martinez \& Dukes, 1997; Neto \& Barros, 2007; Phinney, 1992; Phinney \& Alipuria, 1996; Roberts et al., 1999). Lum (2008), for example, looked at the implications of ethnic identity and ethnic status (monoethnic or multiethnic) on self-esteem, perceived discrimination, life satisfaction, bullying, and antisocial behavior among Malaysian (Malay, Chinese, and Indian) children and adolescents aged 10 to 16, sampling a total of 261 participants from Kuala Lumpur and Petaling Jaya, Malaysia. In relation to ethnic identity and selfesteem, the results of Lum's (2008) study supported her hypothesis that there would be a significant positive relationship between ethnic identity and selfesteem. In addition, Lum (2008) found that the Indian Malaysian adolescents she sampled had a significantly higher mean self-esteem score than the Chinese Malaysian adolescents, which is an interesting finding that is reminiscent of the observations about lower self-reported self-esteem among East Asian/Chinese 
individuals in the studies conducted by Bachman et al. (2011) and Cai et al. (2007).

Hypothesis 2 addressed whether there was a significant difference in ethnic identity scores for students attending the two universities, UM and UTAR. It was predicted that ethnic identity scores would be significantly higher for students at UM compared to UTAR, but the results from the analyses did not support this hypothesis because no statistically significant difference was found. Although a numerical difference in mean score was found when a simple comparison was made between the two universities, with the ethnic identity mean score higher at UM than at UTAR, the difference was not significant.

These results regarding ethnic identity and social context are consistent with the results of Umaña-Taylor and Shin's (2007) study and Juang et al.'s (2006) study. Among Asian American and European American adolescents in California and the Midwest US, the students' numeric majority/minority status was found to have no effect on their ethnic identity (Umaña-Taylor \& Shin, 2007). Similarly, among Asian American university students from the U.S. West Coast and the Midwest US, the students' majority (concentrated) or minority (dispersed) status was again found to have no significant difference on their mean ethnic identity scores (Juang et al., 2006).

These results regarding ethnic identity and social context differ, however, from the results of Xu et al.'s (2015) study and Umaña-Taylor's (2004) study. Among Asian American university students in Hawai'i and California, on the U.S. mainland, significantly higher levels of ethnic identity were reported from Asian Americans in California (where they were a minority group) than from Asian Americans in Hawai'i (where they were in the majority) (Xu et al., 2015). Similarly, among Mexican-origin adolescents in the Southwest of the U.S.A., significantly higher levels of ethnic identity were reported from those students attending a predominately non-Latino high school (where they were a minority group) than from those students attending a predominately Latino high school (where they were in the majority) and from those students attending a balanced Latino/non-Latino high school (Umaña-Taylor, 2004).

\section{Ethnic Identity}

The lack of a significant difference in means for ethnic identity score between the two universities (from Hypothesis 2) led to further investigation into what factors might play a more substantial role in influencing ethnic identity. Multiple regression analysis was conducted including first language, religion, and majority/minority statuses at primary school, secondary school, and university as predictors of students' sense of ethnic identity using the MEIM-R overall score, the "commitment" sub-score, and the "exploration" sub-score as dependent 
variables. For first language, responding with only Chinese (not a combination of languages, such as Chinese and English, for example) was used in the regression. For religion, a group of responses including both Buddhism and Taoism was used in the regression. These responses for first language and religion, along with Chinese majority statuses at the schools, were used because they are considered to be the most strongly in line with the Chinese ethnicity. Regarding majority statuses at schools, not only would these simply be the most highly concentrated Chinese context for students, it also seems reasonable that Chinese Malaysian parents could have intentionally sent their children to Chinese majority schools because this is in line with their high value of education: "In the Chinese tradition, education... is considered an important site of moral and cultural instruction" (Carstens, 2013, p. 32). For all three dependent variables, speaking Chinese as one's first language was a significant predictor, while having Buddhism or Taoism as one's religion was a significant predictor for the MEIM-R overall score and the "exploration" sub-score, and attending a Chinese majority primary school was a significant predictor for the "commitment" subscore.

The predictors of first language, religion, and primary school would all have an influence in the earlier years of one's life, especially in the home and among family, indicating that ethnic identity development seems to happen earlier in life. This agrees with existing theory, which states that ethnic identity development occurs during adolescence (Erikson, 1956; Phinney, 1990). Therefore, it makes sense that university attendance alone (Chinese majority or Chinese minority) was not associated with a significant difference in mean ethnic identity score because university students are just at the end of adolescence or are beyond adolescence. The university students in this study were most likely most influenced by their context and other factors before attending UTAR and UM.

Looking at the commitment subscale specifically, attending a Chinese majority primary school is a significant predictor for ethnic identity commitment. This finding makes sense because at primary school age most individuals most likely do not take any sort of exploration into their own hands, but rather commit somewhat blindly to the ethnic group that surrounds them and to the ethnic identity that is passed on to them from their parents or other authority figures. The ethnic identity status that correlates with this kind of behavior would be described by Phinney et al. (2007) as foreclosed - having strong commitment but lacking exploration. This result regarding the commitment subscale seems to suggest that ethnic identity commitment may happen even earlier in life than exploration for these Chinese Malaysian students. Looking at the exploration 
subscale specifically, identifying with a traditionally Chinese religion such as Buddhism or Taoism is a significant predictor for ethnic identity exploration. This finding makes sense because identifying with a Chinese religion that is full of practices and rituals would often lead to explorative experiences as individuals try out what they see others do and then decide for themselves what they believe and what they will continue to practice. Additionally, religious practices and rituals would most likely occur more by choice or simply once one is old enough to be able to participate, and religious exploration would therefore happen at a slightly older age than the commitment alone mentioned above. Ethnic identity exploration without commitment would be described by Phinney et al. (2007) as moratorium, while the ethnic identity status that includes both exploration and commitment is known as achieved ethnic identity. Using Chinese as one's first language persists as a significant predictor for both the commitment and exploration subscales probably because language continues to be a powerful force and ever-present part of life, especially at home with one's family, throughout one's ethnic identity development.

\section{Ethnic Identity and Self-Esteem}

The data show a significant positive correlation between ethnic identity and selfesteem at both UM and UTAR, although this was only expected at UM. The general finding that ethnic identity and self-esteem are significantly positively correlated suggests the salience of ethnic identity in these students' lives. The lack of a different observation between the two schools seems to suggest that ethnic identity remains salient for Chinese Malaysian university students regardless of the ethnic composition of their university. This finding may be due to the fact that these Chinese Malaysian students are still an ethnic minority within the country of Malaysia, so even if they are a majority at their university they are still a minority in their larger context. This was also the case for the Mexican-origin adolescents in Umaña-Taylor's (2004) study, which produced similar findings.

\section{Conclusion}

The notion of ethnic identity is of particular importance in such an ethnically diverse country as Malaysia. For Chinese Malaysian university students specifically who are from a very large minority group in Malaysia, ethnic identity development is of utmost importance for their well-being and for the health of the country. The statistically significant relationship between ethnic identity and self-esteem for Chinese Malaysian students, including those from both minority and majority university social contexts, supports this truth. 
Recalling that a positive relationship between ethnic identity and self-esteem was observed among ethnic minority adolescents (e.g., Asian, African American, Latino, Native American) in studies conducted by Carlson et al. (2000); Martinez and Dukes (1997); Phillips Smith et al. (1999); Phinney (1992); Phinney and Alipuria (1990); Phinney et al. (1997); Phinney and Chavira (1992); Phinney et al. (1993) and Phinney et al. (1994) among others, similar results from this study about the significant relationship between ethnic identity and self-esteem at both universities suggest that Chinese Malaysian university students are more heavily influenced by their minority status within Malaysia as a whole and less influenced by their majority or minority status within the smaller context of their university.

Additionally, the lack of a statistically significant difference in ethnic identity scores between the two universities along with the regression of language, religion, and education variables on ethnic identity revealed further characteristics of Chinese Malaysian university students' ethnic identity development. Looking at each of the two subscales of the Multigroup Ethnic Identity Measure-Revised separately and at their combined score showed that, in general, ethnic identity is influenced and shaped in an individual's childhood and adolescence, often through one's family at home and through their primary school, rather than during one's university years.

Considering that this study has reinforced the significant impact on Chinese Malaysian ethnic identity development of, first, minority status at a macro (possibly national) level rather than a micro (university) level and, second, factors that come in to play during childhood and adolescence rather than during university years, a next step in the study of ethnic identity for Chinese Malaysians could be based on the cities or states in which individuals grow up as this would look at a scale somewhere between university and nation and would focus on a younger age. Sharon Carstens, prolific researcher about the ethnic Chinese in Malaysia in the field of sociocultural anthropology remarks that there exists a sense of national alienation for Malaysian Chinese individuals in Malaysia, which in turn promotes a stronger identification with specific culturally distinctive locations within Malaysia such as Penang or Sabah (Wang, 2002; Carstens, 2013). This seems to agree with the idea that the state or city in which an individual grew up - whether it is highly ethnically Chinese or not may play a significant role in his or her ethnic identity development.

\section{Acknowledgements}

An earlier version of this paper was presented at the $7^{\text {th }}$ International Conference on Southeast Asia held on 6-7 December 2017 at the Faculty of Arts and Social 
Sciences, University of Malaya, Kuala Lumpur. The authors are grateful to the participants at the conference for their helpful comments.

\section{References}

Abu-Rayya, H. M. (2006). Ethnic identity, ego identity, and psychological wellbeing among mixed ethnic Arab-European adolescents in Israel. British Journal of Developmental Psychology, 24, 669-679.

Ang, R. P., Neubronner, M., Oh, S., \& Leong, V. (2006). Dimensionality of Rosenberg's self-esteem scale among normal-technical stream students in Singapore. Current Psychology, 25, 120-131.

Bachman, J. G., O’Malley, P. M., Freedman-Doan, P., Trzesniewski, K. H., \& Donnellan, M. B. (2011). Adolescent self-esteem: Differences by race/ethnicity, gender, and age. Self and Identity, 10(4), 445-473.

Bracey, J. R., Bamaca, M. Y., \& Umaña-Taylor, A. J. (2004). Examining ethnic identity and self-esteem among biracial and monoracial adolescents. Journal of Youth and Adolescence, 33(2), 123-132.

Cai, H., Brown, J. D., Deng, C., \& Oakes, M. A. (2007). Self-esteem and culture: Differences in cognitive self-evaluations of affective self-regard? Asian Journal of Social Psychology, 10, 162-170.

Carlson, C., Uppal, S., \& Prosser, E. C. (2000). Ethnic differences in processes contributing to the self-esteem of early adolescent girls. Journal of Early Adolescence, 20, 44-67.

Carstens, S. A. (2013). New questions, new directions in Malaysian Chinese studies. In Collected Essays: Malaysian Chinese First Biennial Research Conference (pp. 15-50). Kuala Lumpur: Centre for Malaysian Chinese Studies.

Chin, Y. M. (2013). Ethnic socialization: A case of Malaysian Malay and Chinese public universities students experiences. International Journal of Social Science and Humanity, 3(6), 582-585.

Erikson, E. H. (1956). The problem of ego identity. Journal of the American Psychoanalytic Association, 4, 56-121.

Farruggia, S. P., Chen, C., Greenberger, E., Dmitrieva, J., \& Macek, P. (2004). Adolescent self-esteem in cross-cultural perspective: Testing measurement equivalence and a mediation model. Journal of CrossCultural Psychology, 35, 719-733.

Granhemat, M., Chan, S. H., \& Abdullah, A. N. (2014). Using the multi-ethnic group measure as an indicator of Malaysian ethnic identities. Malaysian Journal of Languages and Linguistics, 3, 31-37. 
Herrington, H. M. (2014). Reliability generalization of the Multigroup Ethnic Identity Measure-Revised (MEIM-R). Undergraduate thesis, Department of Counseling Psychology and Special Education, Brigham Young University, Provo, United States. Retrieved from http://hdl.lib.byu.edu/1877/etd7231

Juang, L. P., Nguyen, H. H., \& Lin, Y. (2006). The ethnic identity, other-group attitudes, and psychosocial functioning of Asian American emerging adults from two contexts. Journal of Adolescent Research, 21, 542-568.

Kurman, J. (2003). Why is self-enhancement low in certain collectivist cultures? An investigation of two competing explanations. Journal of Cross-Cultural Psychology, 34, 496-510.

Kurman, J., \& Sriram, N. (2002). Interrelation ships among vertical and horizontal collectivism, modesty, and self-enhancement. Journal of Cross-Cultural Psychology, 33, 71-86.

Lee, Y. F. (2009). Everyday identities in Malaysian Chinese's subjectivities. Akademika, 75, 21-41.

Lewin, K. (1948). Resolving social conflicts. New York: Harper.

Lum, R. M. Y. (2008). An investigation of the effects of ethnic identity on well-being of monoethnic and multiethnic children and adolescents in Malaysia, Master's thesis, Victoria University of Wellington, Wellington, New Zealand. Retrieved from http://hdl.handle.net/10063/1037

Marcia, J. E. (1966). Development and validation of ego identity status. Journal of Personality and Social Psychology, 3, 551-558.

Martinez, R. O., \& Dukes, R. L. (1997). The effects of ethnic identity, ethnicity, and gender on adolescent well-being. Journal of Youth and Adolescence, 26(5), 503-516.

Nagata, J. (1980). Malaysian mosaic: Perspectives from a polyethnic society. Vancouver: University of British Columbia Press.

Neto, F., \& Barros, J. (2007). Satisfaction with life among adolescents from Portuguese immigrant families in Switzerland. Swiss Journal of Psychology, 66(4), 215-223.

Owens, T. J. (1993). Accentuate the positive-and the negative: Rethinking the use of self-esteem, self-deprecation, and self-confidence. Social Psychology Quarterly, 56(4), 288-299.

Owens, T. J. (1994). Two dimensions of self-esteem: Reciprocal effects of positive self-worth and negative self-esteem on adolescent problems. American Sociological Review, 59, 391-407.

Patton, M. (1990). Qualitative evaluation and research methods. Beverly Hills, CA: Sage. 
Phillips Smith, E., Walker, K., Fields, L., Brookins, C. C., \& Seay, R. C. (1999). Ethnic identity and its relationship to self-esteem, perceived efficacy, and prosocial attitudes in early adolescence. Journal of Adolescence, 22, 867-880.

Phinney, J. S. (1989). Stages of ethnic identity development in minority group adolescents. Journal of Adolescence, 9, 34-39.

Phinney, J. S. (1990). Ethnic identity in adolescents and adults: Review of research. Psychological Bulletin, 108(3), 499-514.

Phinney, J. S. (1992). The multigroup ethnic identity measure: A new scale for use with diverse groups. Journal of Adolescent Research, 7, 156-176.

Phinney, J. S., \& Alipuria, L. L. (1990). Ethnic identity in college students from four ethnic groups. Journal of Adolescence, 13(2), 171-183.

Phinney, J. S., \& Alipuria, L. L. (1996). At the interface of cultures: Multiethnic/multiracial high school and college students. The Journal of Social Psychology, 136(2), 139-158.

Phinney, J. S., Cantu, C. S., \& Kurtz, D. A. (1997). Ethnic and American identity as predictors of self-esteem among African American, Latino and White adolescents. Journal of Youth and Adolescence, 26, 165-185.

Phinney, J. S., \& Chavira, V. (1992). Ethnic identity and self-esteem: An exploratory longitudinal study. Journal of Adolescence, 15, 271-281.

Phinney, J. S., Chavira, V., \& Tate, J. D. (1993). The effect of ethnic threat on ethnic concept and own-group ratings. Journal of Social Psychology, 133, 469-478.

Phinney, J. S., Dupont, S., Espinosa, C., Revill, J., \& Sanders, K. (1994). Ethnic identity and American identification among ethnic minority youths. In M. Bouvy, F. J. R. van de Vijver, P. Boski, \& P. Schmitz (Eds.), Journeys into cross-cultural psychology (pp. 167-183). Amsterdam: Swets \& Zeitlinger B.V.

Phinney, J. S., Jacoby, B., \& Silva, C. (2007). Positive intergroup attitudes: The role of ethnic identity. International Journal of Behavioral Development, 31(5), 478-490.

Phinney, J. S., \& Ong, A. D. (2007). Conceptualization and measurement of ethnic identity: Current status and future directions. Journal of Counseling Psychology, 54(3), 271-281.

Roberts, R. E., Phinney, J. S., Masse, L. C., Chen, Y. R., Roberts, C. R., \& Romero, A. (1999). The structure of ethnic identity in young adolescents from diverse ethnocultural groups.Journal of Early Adolescence, 19(3), 301-322.

Rosenberg, M. (1979). Conceiving the self. New York: Basic Books. 
Schmider, E., Ziegler, M., Danay, E., Beyer, L., \& Bühner, M. (2010). Is it really robust? Rein vestigating the robustness of ANOVA against violations of the normal distribution assumption. Methodology: European Journal of Research Methods for the Behavioral and Social Sciences, 6, 147-151.

Supple, A. J., Su, J., Plunkett, S. W., Peterson, G. W., \& Bush, K. R. (2013). Factor structure of the Rosenberg Self-Esteem Scale. Journal of Cross-Cultural Psychology, 44(5), 748-764.

Tajfel, H., \& Turner, J. C. (1979). An integrative theory of intergroup conflict. In W. G. Austin \& S. Worchel (Eds.), The social psychology of intergroup relations (pp. 33-47). Monterey, CA: Brooks/Cole.

Tan, C. B. (2005). Chinese in Malaysia. In M. Ember, C. R. Ember, \& I. Skoggard (Eds.), Encyclopedia of diasporas (pp. 697-706). New York: Springer US.

The world factbook 2013-14. (2017). Washington, DC: Central Intelligence Agency.

Tierney, W. G., \& Sirat, M. (2008). Challenges facing Malaysian higher education. International Higher Education, 53, 23-24.

Ting, H. M. H. (2014). Social cohesion in Malaysia. In W. Hofmeister \& P. Rueppel (Eds.), Social cohesion: Addressing social divide in Europe and Asia (pp. 59-74). Singapore: Konrad-Adenauer Stiftung Ltd.

Tsai, J. L., Chentsova-Dutton, Y., \& Wong, Y. (2002). Why and how researchers should study ethnic identity, acculturation, and cultural orien tation. In G. C. Nagayama Hall \& S. Okazaki (Eds.), Asian American psychology: The science of lives in context (pp. 41-65). Washington, DC: American Psychological Association.

Umaña-Taylor, A. J. (2004). Ethnic identity and self-esteem: examining the role of social context. Journal of Adolescence, 27, 139-146.

Umaña-Taylor, A. J., \& Shin, N. (2007). An examination of ethnic identity and self-esteem with diverse populations: Exploring variation by ethnicity and geography. Cultural Diversity and Ethnic Minority Psychology, 13, 178-186.

Wan Husin, W. N. (2013). Business dominance among the Malays and Chinese in Malaysia from a civilizational perspectives. International Journal of Social Science and Humanity, 3(4), 360-364.

Wang, G. W. (2002). Local and national: A dialogue between tradition and modernity. In L. Suryadinata (Ed.), Ethnic Chinese in Singapore and Malaysia: Adialogue between tradition and modernity (pp. 1-9). Singapore: Times Academic Press.

Whetstone, M. R., Okun, M. A., \& Cialdini, R. B. (1992, 20-22 June). The modest responding scale. Paper presented at the convention of the American Psychological Society, San Diego, United States. 
Xu, Y., Farver, J. M., \& Pauker, K. (2015). Ethnic identity and self-esteem among Asian and European Americans: When a minority is the majority and the majority is a minority. European Journal of Social Psychology, 45, 62-76. 